\title{
The association of acute kidney injury with hospital readmission and death after pediatric cardiac surgery
}

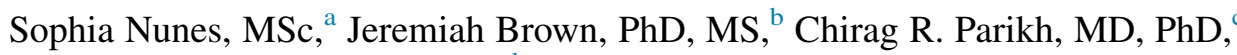
Jason H. Greenberg, MD, MHS, ${ }^{\mathrm{d}}$ Prasad Devarajan, MD, ${ }^{\mathrm{e}}$ Heather Theissen Philbrook, PhD, MMath, Michael Pizzi, BSc, ${ }^{\mathrm{f}}$ Ana Palijan, PhD, MS, ${ }^{\mathrm{f}}$ and Michael Zappitelli, MD, MSc ${ }^{\mathrm{a}, \mathrm{g}}$

\section{ABSTRACT}

Background: Acute kidney injury (AKI) in children undergoing cardiac surgery (CS) is strongly associated with increased hospital mortality and length of stay. The association of AKI with postdischarge outcomes is unclear. We evaluated the association of AKI with all-cause readmissions and death within 30 days and 1 year of CS discharge.

Methods: This was a prospective, 3-center cohort study of children after CS with cardiopulmonary bypass. The primary exposures were postoperative $\geq$ stage 1 AKI and $\geq$ stage 2 AKI defined by Kidney Disease: Improving Global Outcomes AKI definition. Two separate outcomes were hospital readmission and death within 30 days and 1 year of discharge. Association of AKI with time to outcomes was determined using multivariable Cox-proportional hazards analysis. Age, The Society of Thoracic Surgeons-European Association for Cardio-Thoracic Surgery risk adjustment tool score $\geq 3$, cardiopulmonary bypass $>120$ minutes, and cyanotic heart disease were evaluated as effect modifiers.

Results: Of 402 participants included (median age 1.8 years [interquartile range 0.4 , $5.2]), 32(8.0 \%)$ and $109(27.1 \%)$ were readmitted; $7(1.7 \%)$ and $9(2.2 \%)$ died within 30 days and 1 year of CS, respectively. AKI was not associated with readmission at 30 days or 1 year postdischarge. $\geq$ Stage 2 AKI (adjusted hazard ratio, 11.68 $[1.88,72.61])$ was associated with mortality 30 days post-CS.

Conclusions: Postoperative AKI was not associated with readmission at 30 days and 1-year postdischarge. However, more severe AKI ( $\geq$ stage 2) appears to be associated with increased morality risk at 30 days post-CS. (JTCVS Open 2020;4:70-85)

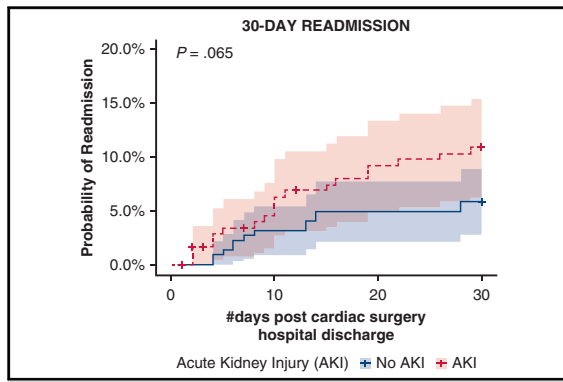

Postoperative AKI is not associated with readmission at 30 days after pediatric CS.

\section{CENTRAL MESSAGE}

Children with severe AKI ( $\geq$ stage

2) after cardiac surgery are at a

higher risk for mortality, but not

readmission, within 30 days of discharge, compared with children without AKI.

\section{PERSPECTIVE}

Reducing postoperative readmission and death is a priority. This is the first prospective cohort study to evaluate the relationship between AKI and post-cardiac surgery discharge readmission in children. Identifying risk factors for readmission and death may enable targeted follow up of atrisk groups and potentially decrease long-term morbidity and mortality.

See Commentaries on pages 86 and 88.
From ${ }^{\mathrm{a} C h i l d ~ H e a l t h ~ E v a l u a t i v e ~ S c i e n c e s ~ a n d ~}{ }^{\mathrm{g}}$ Department of Pediatrics, The Hospital for Sick Children, Toronto, Ontario, Canada; ${ }^{b}$ Departments of Epidemiology and Biomedical Data Science, Geisel School of Medicine at Dartmouth, Hanover, $\mathrm{NH} ;{ }^{\mathrm{c}}$ Division of Nephrology, Johns Hopkins University School of Medicine, Baltimore, Md; ${ }^{\mathrm{d}}$ Section of Nephrology, Department of Pediatrics, Yale University School of Medicine, New Haven, Conn; ${ }^{~}$ Nephrology and Hypertension, Cincinnati Children's Hospital Medical Center, Cincinnati, Ohio; and ${ }^{\mathrm{f}} \mathrm{McGill}$ University Health Research Institute Centre, Montreal, Québec, Canada.

This study was supported by National Institutes of Health (NIH) grant RO1HL085757 to fund the TRIBE-AKI Consortium and supported data collection in this study (C.R.P. is the primary author). J.B is supported by National Heart, Lung, and Blood Institute and National Institute of Diabetes and Digestive and Kidney Diseases (NIDDK) grants. J.H.G. is funded by the NIDDK career development grant K08DK110536 (supported data collection for this study) and by the Charles $\mathrm{H}$. Hood Foundation, Inc, Boston, Mass. P.D. is supported by NIH grant
P50DK096418. MZ was supported by a Fond de Recherche due Quebec - Sante (FRQ-S) research salary award during the majority of the time this work was performed.

Received for publication July 8, 2020; revisions received July 8, 2020; accepted for publication July 20, 2020; available ahead of print Aug 28, 2020.

Address for reprints: Michael Zappitelli, MD, MSc, The Hospital for Sick Children, Peter Gilgan Centre for Research and Learning, 686 Bay St, 11th Floor, Room 11.9722, Toronto, Ontario, M5G0A4 Canada (E-mail: Michael.Zappitelli@ sickkids.ca).

2666-2736

Copyright $(2020$ The Authors. Published by Elsevier Inc. on behalf of The American Association for Thoracic Surgery. This is an open access article under the CC BY-NCND license (http://creativecommons.org/licenses/by-nc-nd/4.0/).

https://doi.org/10.1016/j.xjon.2020.07.006 


\section{Abbreviations and Acronyms \\ aHR = adjusted hazard ratio \\ AKI $=$ acute kidney injury \\ CI $=$ confidence interval \\ $\mathrm{CKD}=$ chronic kidney disease \\ $\mathrm{CPB}=$ cardiopulmonary bypass \\ $\mathrm{SCr}=$ serum creatinine \\ STAT $=$ The Society of Thoracic Surgeons- \\ European Association for Cardio- \\ Thoracic Surgery risk adjustment tool \\ TRIBE AKI $=$ Translational Research Investigating Biomarker Endpoints in Acute Kidney Injury}

Acute kidney injury (AKI) occurs in $25 \%$ to $60 \%$ of children undergoing cardiac surgery and is strongly associated with increased hospital morbidity. ${ }^{1,2}$ In adults undergoing cardiac surgery, postoperative AKI has been shown to be associated with postdischarge mortality, cardiovascular events, development of chronic kidney disease (CKD), and end-stage renal disease. ${ }^{3-7}$ In noncardiac surgery children admitted to the intensive care unit, AKI has also been shown to be associated with increased health care use at 1 year postdischarge. ${ }^{8}$ In a retrospective study of children undergoing cardiac surgery, a strong association of AKI with CKD development 1 to 3 years postdischarge was shown. ${ }^{9}$ However, there is a lack of published data on the extent to which AKI after pediatric cardiac surgery is associated with non-kidney outcomes, including morbidity or health care use. Given data published in other patient populations, this association is important to elucidate as AKI after cardiac surgery may negatively impact long-term health, independent of a potential relationship with CKD and hypertension development. Previous clinical and epidemiologic research has demonstrated mechanisms between AKI and subsequent pulmonary, cardiac, and neurologic dysfunction that may contribute to morbidity and mortality after hospital discharge. ${ }^{10,11}$ Exploring health care use after cardiac surgery-associated AKI may also provide insight into long-term health burden for these patients, resource allocation, and health care use patterns. Finally, it is possible that the association of AKI with health care use and mortality is modified by factors known to affect long-term outcomes in children undergoing cardiac surgery, including age, cardiac surgery complexity, cardiopulmonary bypass (CPB) time, and cyanotic heart disease. ${ }^{1,12,13}$

The goal of this study was to determine whether postoperative cardiac surgery-associated AKI is associated with increased risk for readmission to hospital and with death, within 30 days and 1 year after pediatric cardiac surgery discharge. A second goal was to determine whether the association of AKI with these outcomes is modified by age, surgical risk score, CPB time, and cyanotic heart disease.

\section{METHODS}

\section{Design, Setting, and Patient Selection}

This study was a secondary analysis of a prospective multicenter cohort study of children undergoing cardiac surgery with cardiopulmonary bypass at Cincinnati Children's Hospital, Montreal Children's Hospital, and Yale New Haven Children's Hospital. Children aged 1 month to 18 years undergoing cardiac surgery were enrolled between July 2007 and December 2010 in the Translational Research Investigating Biomarker Endpoints in AKI (TRIBE-AKI) study. Children with renal transplantation, dialysis, or the presence of AKI before cardiac surgery were excluded. Detailed patient recruitment methods for this study have been published elsewhere. ${ }^{1,14}$ Previously published TRIBE-AKI studies included children enrolled over 3 years (to 2009); this cohort includes an additional year of enrollment (to 2010). Parents or legal guardians of participants provided informed consent to participate and children provided assent when appropriate (age $>7$ years old). Research ethics board (Canada) and internal review board (United States) approvals were obtained from each institution before initiating study activities (ethics approval REB \#1000061924; expiration date: 2020-09-28).

\section{Data Collected From the Index Cardiac Surgery Admission From the Prospective TRIBE-AKI Study}

After preoperative recruitment, baseline variables collected included age at surgery, sex, previous cardiac surgeries, presence of cyanotic heart disease, congenital heart defect type, and noncardiac abnormalities. Participants were classified with cyanotic heart disease through review of surgical and defect type. Surgery-related variables collected included urgent versus elective surgery, risk adjustment using The Society of Thoracic Surgeons-European Association for Cardio-Thoracic Surgery (STAT) score (categorizes mortality risk associated with congenital heart surgery procedures on a scale of 1 to 5 with 1 being associated with the lowest mortality risk), ${ }^{15}$ CPB time, and duration of aortic crossclamp use. Postoperative variables collected prospectively while in hospital included (but were not limited to): daily serum creatinine ( $\mathrm{SCr}$ ), length of intensive care unit stay, length of hospital stay, and hospital mortality.

\section{Primary Exposure Definition: Postoperative AKI}

The presence of postoperative AKI during index cardiac surgery admission was defined based on the $\mathrm{SCr}$ criteria of the Kidney Disease: Improving Global Outcomes guidelines definition. ${ }^{16}$ Stage 1 AKI was a $\mathrm{SCr}$ rise of 1.5 to $<2$ times baseline $\mathrm{SCr}$ within 7 days or a $\geq 0.3 \mathrm{mg} / \mathrm{dL}$ $(26.5 \mu \mathrm{mo} / \mathrm{L})$ rise from baseline $\mathrm{SCr}$ within 48 hours; stage 2 AKI was $\mathrm{SCr}$ rise to 2.0 to $<3$ times baseline $\mathrm{SCr}$; stage $3 \mathrm{AKI}$ was $\mathrm{SCr}$ rise to $\geq 3$ times baseline $\mathrm{SCr}$ or receiving acute dialysis for $\mathrm{AKI}$ or a decrease of estimated glomerular filtration rate to less than $35 \mathrm{~mL} / \mathrm{min} / 1.73 \mathrm{~m}^{2}$ for children over 3 months. The primary exposures were the presence of any AKI ( $\geq$ stage 1$)$ and the presence of severe AKI ( $\geq$ stage 2$)$.

\section{Outcome Definitions: 30-Day and 1-Year Rehospitalization and Death}

Outcome data were collected retrospectively by medical chart and hospital electronic health records review, in addition to consultation with the cardiology services who cared for the patients. The 2 separate outcomes were rehospitalization for any reason and all-cause mortality at 30 days 


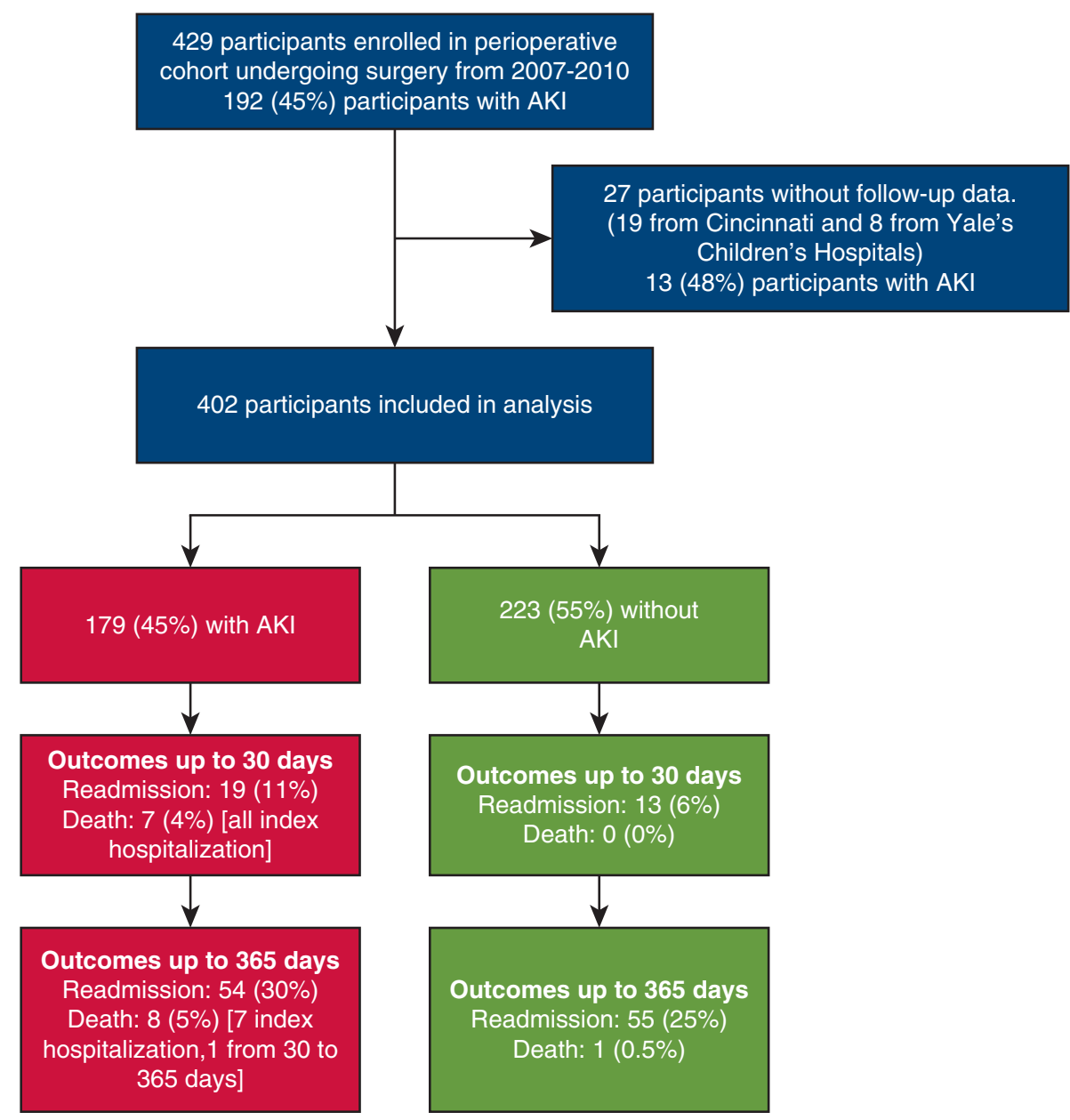

FIGURE 1. Sample flow chart. A total of 429 patients undergoing cardiac surgery between 2007 and 2010 were included in the TRIBE-AKI study. In total, 27 patients (19 from Cincinnati Children's Hospital and 8 from Yale's Children's Hospital) were excluded due to lack of follow-up data, resulting in a total of 402 participants included in the analysis. 179 (45\%) participants developed AKI during index admission. Nineteen (11\%) and 54 (30\%) participants with postoperative AKI were readmitted within 30 days and 1 year of cardiac surgery discharge, respectively. Seven (4\%) and 8 (5\%), 7 from index admission and 1 from 30 to 365 days, participants with postoperative AKI died within 30 days and 1 year, respectively. Thirteen (6\%) and 55 (25\%) participants without postoperative AKI were readmitted within 30 days and 1 year of discharge, respectively. Zero and $1(0.5 \%)$ participants without postoperative AKI died within 30 days and 1 year, respectively. AKI, Acute kidney injury.

and 1-year postdischarge. One-year outcomes include all events up to and within the first 30 days as well as events from 30 to 365 days. Index admission and postdischarge deaths were included in mortality analyses. Descriptive data on primary diagnoses for rehospitalizations were collected and categorized for descriptive purposes.

\section{Statistical Analysis}

Characteristics of patients with versus without each of the outcomes at 30 days and 1 year and of patients with versus without postoperative AKI were compared. Continuous variables were compared using $t$ tests or Wilcoxon rank sum tests and categorical variables were compared using $\chi^{2}$ tests or Fisher exact tests, as appropriate. The associations of postoperative $\geq$ stage $1 \mathrm{AKI}, \geq$ stage $2 \mathrm{AKI}$, and the increasing AKI stage (no AKI to stage 3 ) with time to readmission were evaluated using multivariable Cox proportional hazards analysis using Fine and Gray's subdistribution method (with death as a competing event). In a sensitivity analysis, the association of AKI with 1-year readmission, only in patients still alive at 30 days, was also analyzed. Regular causespecific Cox proportional hazards models were used to analyze associations of AKI with mortality. Covariates to include in the multivariable models were selected a priori based on known risk factors for AKI in this population and also by examining univariable associations of patient characteristics with readmission and mortality. Age (continuous), STAT score $\geq 3$, CPB time $>120$ minutes, and cyanotic heart disease were included with AKI in multivariable models. Effect modification of the associations between AKI and the outcomes were evaluated for age $>1$, STAT surgical severity score $\geq 3$, presence of CPB time $>120$ minutes and cyanotic heart disease by including interaction terms of AKI with each of these variables. SAS, version 9.4 (SAS Institute, Inc, Cary, NC) was used to conduct analyses.

\section{RESULTS}

\section{Cohort Characteristics}

A total of 429 patients undergoing cardiac surgery between 2007 and 2010 were included in the TRIBE-AKI study (Figure 1). Of these, 402 participants had available readmission and mortality data at 1 year and were included in 
TABLE 1. Patient characteristics by readmission at 30 days postcardiac surgery

\begin{tabular}{|c|c|c|c|c|}
\hline \multirow[b]{2}{*}{ Patient characteristics } & \multicolumn{4}{|c|}{ Number $(\%)$, mean (SD) or median (IQR) } \\
\hline & Overall $(n=402)$ & No readmission at $30 \mathrm{~d}(\mathrm{n}=370)$ & Readmission at $30 \mathrm{~d}(\mathrm{n}=32)$ & $P$ value \\
\hline \multicolumn{5}{|l|}{ Preoperative/baseline variables } \\
\hline Age, $\mathrm{y}-$ continuous & $1.8(0.4,5.2)$ & $1.99(0.44,5.29)$ & $0.76(0.47,4.21)$ & .580 \\
\hline \multicolumn{5}{|l|}{ Age - categorized } \\
\hline $31 \mathrm{~d}$ to $\leq 1 \mathrm{y}$ & $179(45 \%)$ & $162(44 \%)$ & $17(53 \%)$ & .308 \\
\hline$>1$ to $<18 \mathrm{y}$ & $223(55 \%)$ & $208(56 \%)$ & $15(47 \%)$ & \\
\hline Female sex & $192(48 \%)$ & $179(48 \%)$ & $13(41 \%)$ & .400 \\
\hline Previous cardiothoracic operations & $165(42 \%)$ & $151(41 \%)$ & $14(45 \%)$ & .690 \\
\hline Cyanotic heart disease & $134(35 \%)$ & $119(34 \%)$ & $15(52 \%)$ & .057 \\
\hline Noncardiac abnormalities & $101(26 \%)$ & $91(25 \%)$ & $10(32 \%)$ & .374 \\
\hline \multicolumn{5}{|l|}{ Surgery-related variables } \\
\hline \multicolumn{5}{|l|}{ STAT category (dichotomized) } \\
\hline$<3$ & $359(90 \%)$ & $332(90 \%)$ & $27(87 \%)$ & .612 \\
\hline$\geq 3$ & $41(10 \%)$ & $37(10 \%)$ & $4(13 \%)$ & \\
\hline \multicolumn{5}{|l|}{ Surgery type } \\
\hline Septal defect repair & $134(35 \%)$ & $124(35 \%)$ & $10(33 \%)$ & .850 \\
\hline Inflow/outflow tract or valve procedure & $62(16 \%)$ & $56(16 \%)$ & $6(20 \%)$ & \\
\hline Combined procedure & $184(48 \%)$ & $170(49 \%)$ & $14(47 \%)$ & \\
\hline \multicolumn{5}{|l|}{ Urgency of surgery } \\
\hline Elective & $368(92 \%)$ & $340(92 \%)$ & $28(88 \%)$ & .392 \\
\hline Urgent & $34(8 \%)$ & $30(8 \%)$ & $4(13 \%)$ & \\
\hline CPB time, $\min$ & $105.78(60.01)$ & $104.51(59.39)$ & $104.51(59.39)$ & .106 \\
\hline $\mathrm{CPB}$ time $>120, \min$ & $126(31 \%)$ & $112(30 \%)$ & $14(44 \%)$ & .115 \\
\hline Crossclamp time, min & $45.85(44.08)$ & $46.15(44.06)$ & $42.41(44.93)$ & .551 \\
\hline \multicolumn{5}{|l|}{ Postoperative variables } \\
\hline Length of ICU stay, d & $2(1,4)$ & $2(1,4)$ & $3(2,5)$ & .079 \\
\hline Length of hospital stay, $d$ & $5(4,9)$ & $5(3,9)$ & $7(5.5,10.5)$ & .010 \\
\hline \multicolumn{5}{|l|}{ KDIGO AKI stages } \\
\hline No AKI & $223(55 \%)$ & $210(57 \%)$ & $13(41 \%)$ & .334 \\
\hline Stage 1 AKI & $121(30 \%)$ & $109(29 \%)$ & $12(38 \%)$ & \\
\hline Stage 2 AKI & $23(6 \%)$ & $20(5 \%)$ & $3(9 \%)$ & \\
\hline Stage 3 AKI & $35(9 \%)$ & $31(8 \%)$ & $4(13 \%)$ & \\
\hline
\end{tabular}

Categorical variables are reported as n (\%) and continuous variables are reported as mean (SD) or median (IQR). SD, Standard deviation; IQR, interquartile range; STAT, The Society of Thoracic Surgeons-European Association for Cardio-Thoracic Surgery risk adjustment tool; $C P B$, cardiopulmonary bypass; ICU, intensive care unit; KDIGO, Kidney Disease: Improving Global Outcomes; $A K I$, acute kidney injury.

the analyses (19 participants from Cincinnati and 8 from Yale's Children's Hospitals were excluded due to lack of follow-up data). The median age of participants was 1.8 years (interquartile range $0.4,5.2)$, with $179(45 \%)$ participants younger than the age of 1 year. One-hundred ninety-two children $(48 \%)$ were female, $41(10 \%)$ participants had a STAT score $\geq 3$ and $126(31 \%)$ had a CPB time $>120$ minutes (Table 1). One hundred seventy-nine (45\%) patients developed postoperative $\geq$ stage 1 AKI, with 58 $(14 \%)$ patients having $\geq$ stage 2 AKI during index admission (Table 1). Five (1\%) patients required renalreplacement therapy during index admission. Appendix Table 1 shows AKI ( $\geq$ stage $1 \mathrm{AKI}$ ) versus non-AKI cohort characteristics comparisons.

In the complete cohort, there were $32(8.0 \%)$, and 109 $(27.1 \%)$ readmissions to hospital within 30 days and 1 year of discharge, respectively. Tables 1 and 2 show that few index cardiac surgery hospitalization variables were associated with 30-day readmission, whereas younger age, presence of cyanotic heart disease, presence of non-cardiac abnormalities, STAT score $\geq 3$, and greater CPB time were associated with 1 -year readmission. Seven $(1.7 \%)$ participants died within 30 days of discharge (all index admission) after cardiac surgery and $9(2.2 \%)$ participants died within 365 days of discharge ( 2 additional deaths from 30 to 365 days). Table 3 and Appendix Table 2 show that CPB time $>120$ minutes and STAT score $\geq 3$ were associated with 30-day and with 1-year mortality in univariable analyses. Combined surgical procedures (vs not) were associated with 1-year mortality (Appendix Table 2).

Appendix Table 3 shows that the most common reasons for readmission in patients with postoperative AKI were cardiac issues or procedures $(31 \%)$, followed by other $(26 \%)$, 
TABLE 2. Patient characteristics by readmission status at 1-year postcardiac surgery

\begin{tabular}{|c|c|c|c|c|}
\hline \multirow[b]{2}{*}{ Patient characteristics } & \multicolumn{4}{|c|}{ Number (\%), mean (SD) or median (IQR) } \\
\hline & Overall $(n=402)$ & No readmission at 1 y $(n=293)$ & Readmission at 1 y $(n=109)$ & $P$ value \\
\hline \multicolumn{5}{|l|}{ Preoperative/baseline variables } \\
\hline Age, $\mathrm{y}-$ continuous & $3.76(4.51)$ & $4.04(4.55)$ & $3.01(4.35)$ & .008 \\
\hline \multicolumn{5}{|l|}{ Age - categorized } \\
\hline $31 \mathrm{~d}$ to $\leq 1 \mathrm{y}$ & $179(45 \%)$ & $118(40 \%)$ & $61(56 \%)$ & .005 \\
\hline$>1 \mathrm{y}$ to $<18 \mathrm{y}$ & $223(55 \%)$ & $175(60 \%)$ & $48(44 \%)$ & \\
\hline Female sex & $192(48 \%)$ & $144(49 \%)$ & $48(44 \%)$ & .362 \\
\hline Previous cardiothoracic operations & $165(42 \%)$ & $117(40 \%)$ & $48(45 \%)$ & .392 \\
\hline Cyanotic heart disease & $134(35 \%)$ & $89(32 \%)$ & $45(45 \%)$ & .025 \\
\hline Noncardiac abnormalities & $101(26 \%)$ & $60(21 \%)$ & $41(39 \%)$ & $<.001$ \\
\hline \multicolumn{5}{|l|}{ Surgery-related variables } \\
\hline \multicolumn{5}{|l|}{ STAT category (dichotomized) } \\
\hline$<3$ & $359(90 \%)$ & $272(93 \%)$ & $87(81 \%)$ & $<.001$ \\
\hline$\geq 3$ & $41(10 \%)$ & $21(7 \%)$ & $20(19 \%)$ & \\
\hline \multicolumn{5}{|l|}{ Surgery type } \\
\hline Septal defect repair & $134(35 \%)$ & $98(35 \%)$ & $36(35 \%)$ & .437 \\
\hline Inflow/outflow tract or valve procedure & $62(16 \%)$ & $49(18 \%)$ & $13(13 \%)$ & \\
\hline Combined procedure & $184(48 \%)$ & $130(47 \%)$ & $54(52 \%)$ & \\
\hline \multicolumn{5}{|l|}{ Urgency of surgery } \\
\hline Elective & $368(92 \%)$ & $270(92 \%)$ & $98(90 \%)$ & .473 \\
\hline Urgent & $34(8 \%)$ & $23(8 \%)$ & $11(10 \%)$ & \\
\hline $\mathrm{CPB}$ time, $\min$ & $105.78(60.01)$ & $101.07(55.02)$ & $118.44(70.46)$ & .017 \\
\hline $\mathrm{CPB}$ time $>120 \mathrm{~min}$ & $126(31 \%)$ & $87(30 \%)$ & $39(36 \%)$ & .242 \\
\hline Crossclamp time, $\min$ & $45.85(44.08)$ & $43.74(41.88)$ & $51.5(49.27)$ & .235 \\
\hline \multicolumn{5}{|l|}{ Postoperative variables } \\
\hline Length of ICU stay, d & $2(1,4)$ & $2(1,4)$ & $3(2,6)$ & $<.001$ \\
\hline Length of hospital stay, $d$ & $5(4,9)$ & $5(3,7)$ & $7(5,14)$ & $<.001$ \\
\hline \multicolumn{5}{|l|}{ KDIGO AKI stages } \\
\hline No AKI & $223(55 \%)$ & $168(57 \%)$ & $55(50 \%)$ & .668 \\
\hline Stage 1 AKI & $121(30 \%)$ & $85(29 \%)$ & $36(33 \%)$ & \\
\hline Stage 2 AKI & $23(6 \%)$ & $16(5 \%)$ & $7(6 \%)$ & \\
\hline Stage 3 AKI & $35(9 \%)$ & $24(8 \%)$ & $11(10 \%)$ & \\
\hline
\end{tabular}

Categorical variables are reported as $\mathrm{n}(\%)$ and continuous variables are reported as mean (SD) or median (IQR). SD, Standard deviation; IQR, interquartile range; STAT, The Society of Thoracic Surgeons-European Association for Cardio-Thoracic Surgery risk adjustment tool; $C P B$, cardiopulmonary bypass; $I C U$, intensive care unit; $K D I G O$, Kidney Disease: Improving Global Outcomes; AKI, acute kidney injury.

and then gastrointestinal and infectious (non-gastroenteritis) (11\% each). In patients without AKI, the most common reasons for readmission were somewhat similar, with cardiac issues or procedures $(25 \%)$, other $(25 \%)$, and then ear-nose-throat $(16 \%)$, and respiratory $(11 \%)$.

\section{Association of AKI With Readmission at 30 Days and 1-Year Postdischarge}

Kaplan-Meir curves in Figure 2 show that there was no statistically significant univariable association between $\mathrm{AKI}$ and readmission within 30 days or within 1 year of cardiac surgery. Table 4 shows that in adjusted analyses (adjusting for age, STAT surgical severity score $\geq 3$, CPB time $>120$ minutes, and cyanotic heart disease), the lack of statistically significant association of postoperative $\geq$ stage $1 \mathrm{AKI}$ or $\geq$ stage 2 AKI with 30-day and 1-year readmission persisted. In the adjusted models, STAT score $\geq 3$ was associated with 1-year readmission postcardiac surgery (adjusted hazard ratio [aHR], 2; 95\% confidence interval [CI], 1.17-3.43; Appendix Table 4). In a sensitivity analysis including only children who survived to 30 days postcardiac surgery, there was again no statistically significant association between AKI and 1-year readmission (Appendix Table 5 and Appendix Figure 1).

\section{Association of AKI With Mortality at 30 Days and 1-Year Postdischarge}

Table 5 and Figure 3 show that postoperative $\geq$ stage 2 AKI was associated with time to mortality within 30 days of cardiac surgery (in adjusted analyses, aHR, 11.68; $95 \%$ CI, 1.88-72.61). Appendix Table 6 shows that of other covariates adjusted for in the models, age (aHR, 1.18; $95 \%$ CI, 1.05-1.33) was also associated with time to mortality at 30 days postdischarge. One-year mortality multivariable 
TABLE 3. Patient characteristics by mortality status at 30 days postcardiac surgery

\begin{tabular}{|c|c|c|c|c|}
\hline \multirow[b]{2}{*}{ Patient characteristics } & \multicolumn{4}{|c|}{ Number (\%), mean (SD), or median (IQR) } \\
\hline & Overall $(n=402)$ & No mortality at $30 \mathrm{~d}(\mathrm{n}=395)$ & Mortality at $30 \mathrm{~d}(\mathrm{n}=7)$ & $P$ value \\
\hline \multicolumn{5}{|l|}{ Preoperative/baseline variables } \\
\hline Age, $\mathrm{y}-$ continuous & $1.8(0.44,5.23)$ & $1.79(0.44,5.08)$ & $8.54(0.25,17.54)$ & .294 \\
\hline \multicolumn{5}{|l|}{ Age - categorized } \\
\hline $31 \mathrm{~d}$ to $1 \mathrm{y}$ & $179(45 \%)$ & $176(45 \%)$ & $3(43 \%)$ & .929 \\
\hline$>1$ to $<18$ y & $223(55 \%)$ & $219(55 \%)$ & $4(57 \%)$ & \\
\hline Female sex & $192(48 \%)$ & $188(48 \%)$ & $4(57 \%)$ & 616 \\
\hline Cyanotic heart disease & $134(35 \%)$ & $131(35 \%)$ & $3(43 \%)$ & .679 \\
\hline Previous cardiothoracic operations & $165(42 \%)$ & $162(42 \%)$ & $3(43 \%)$ & .953 \\
\hline Noncardiac abnormalities & $101(26 \%)$ & $98(25 \%)$ & $3(43 \%)$ & .290 \\
\hline \multicolumn{5}{|l|}{ Surgery-related variables } \\
\hline \multicolumn{5}{|l|}{ STAT category (dichotomized) } \\
\hline$<3$ & $359(90 \%)$ & $355(90 \%)$ & $4(57 \%)$ & .004 \\
\hline$\geq 3$ & $41(10 \%)$ & $38(10 \%)$ & $3(43 \%)$ & \\
\hline \multicolumn{5}{|l|}{ Surgery type } \\
\hline Septal defect repair & $134(35 \%)$ & $134(36 \%)$ & $0(0 \%)$ & .101 \\
\hline Inflow/outflow tract or valve procedure & $62(16 \%)$ & $61(16 \%)$ & $1(14 \%)$ & \\
\hline Combined procedure & $184(48 \%)$ & $178(48 \%)$ & $6(86 \%)$ & \\
\hline \multicolumn{5}{|l|}{ Urgency of surgery } \\
\hline Elective & $368(92 \%)$ & $363(92 \%)$ & $5(71 \%)$ & .054 \\
\hline Urgent & $34(8 \%)$ & $32(8 \%)$ & $2(29 \%)$ & \\
\hline CPB time, min & $105.78(60.01)$ & $104.15(57.08)$ & $197.57(129.26)$ & .023 \\
\hline $\mathrm{CPB}$ time $>120 \mathrm{~min}$ & $126(31 \%)$ & $120(30 \%)$ & $6(86 \%)$ & .002 \\
\hline Crossclamp time, min & $45.85(44.08)$ & $45.82(43.93)$ & $47.86(56.25)$ & .901 \\
\hline \multicolumn{5}{|l|}{ Postoperative variables } \\
\hline Length of ICU stay, d & $2(1,4)$ & $2(1,4)$ & $4.5(2,12)$ & .242 \\
\hline Length of hospital stay, $\mathrm{d}$ & $5(4,9)$ & $5(4,9)$ & $3(2,12)$ & .272 \\
\hline \multicolumn{5}{|l|}{ KDIGO AKI stages } \\
\hline No AKI & $223(55 \%)$ & $223(56 \%)$ & $0(0 \%)$ & $<.001$ \\
\hline Stage 1 AKI & $121(30 \%)$ & $119(30 \%)$ & $2(29 \%)$ & \\
\hline Stage 2 AKI & $23(6 \%)$ & $22(6 \%)$ & $1(14 \%)$ & \\
\hline Stage 3 AKI & $35(9 \%)$ & $31(8 \%)$ & $4(57 \%)$ & \\
\hline
\end{tabular}

Categorical variables are reported as n (\%) and continuous variables are as reported mean (SD) or median (IQR). SD, Standard deviation; IQR, interquartile range; STAT, The Society of Thoracic Surgeons-European Association for Cardio-Thoracic Surgery risk adjustment tool; $C P B$, cardiopulmonary bypass; ICU, intensive care unit; KDIGO, Kidney Disease: Improving Global Outcomes; $A K I$, acute kidney injury.

results were not performed due to the low number of events ( 2 deaths) between 30 days and 1-year postdischarge.

\section{Evaluation of Effect Modification of the Association of AKI With Outcomes}

Appendix Table 7 shows that neither age $>1$ year, STAT surgical severity score $\geq 3, \mathrm{CPB}>120$ minutes, nor cyanotic heart disease modified the relationship between AKI with mortality or with hospitalizations (all interaction term $P$ values $>.1$ ).

\section{DISCUSSION}

Decreasing readmission and mortality after cardiac surgery has been identified as a priority by government programs and bodies such as Medicare (United States) and Ontario Ministry of Health and Long Term Care (Canada) to improve patient outcomes and reduce health care costs. ${ }^{17,18}$ Currently, readmission rates after cardiac surgery are high, with approximately $10 \%$ to $20 \%$ of children being readmitted within 30 days of discharge. ${ }^{19,20}$ Identification of risk factors for long-term readmission and mortality would allow for close follow-up and targeted interventions in at-risk groups. In the present study, AKI during index admission was not associated with readmission to hospital within 30 days or 1 year of hospital discharge as shown in the Figure 4 . $\geq$ Stage 2 AKI was associated with a greater risk of death within 30 days of discharge. Only a limited number of studies in children undergoing cardiac surgery have evaluated long-term readmission, and this is the first prospective cohort study to evaluate the association between postoperative AKI with readmission after pediatric cardiac surgery.

We found that $8 \%$ of our cohort was readmitted within 30 days, which does not differ significantly from other studies conducted on children after cardiac surgery. ${ }^{13,20}$ This study did not find an association 

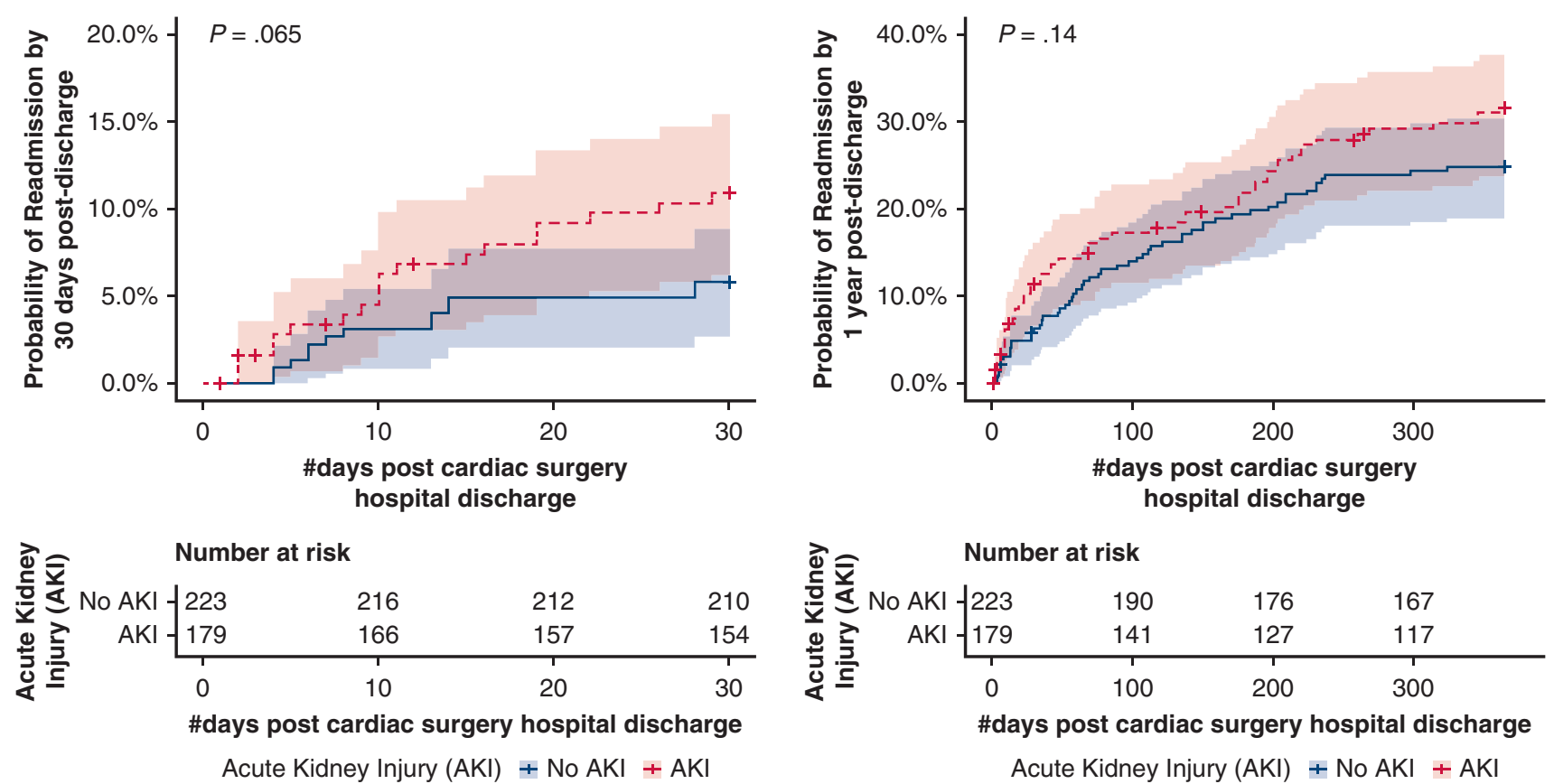

A

Acute Kidney Injury (AKI) + No AKI + AKI

FIGURE 2. Kaplan-Meier curves for readmission within 30 days and 1 year by AKI status. Panels A and B are survival curves for the outcome of readmission by 30 days (A) and 1 year (B) after index cardiac surgery discharge in this cohort (402 patients). A, The dotted red line represents patients with postoperative AKI and the blue line represents patients without postoperative AKI. The red-and blue-shaded areas represent the confidence intervals for the AKI and non-AKI group, respectively. There is no statistically significant difference between the 2 survival curves (log-rank test $P=.065$ ). B, The dotted red line represents patients with postoperative AKI; the blue line represents patients without postoperative AKI. The red-and blue-shaded areas represent the confidence intervals for the AKI and non-AKI group respectively. There is no statistically significant difference across survival curves (logrank test $P=.14)$. AKI, Acute kidney injury.

between AKI and readmission outcomes at 30 days postcardiac surgery discharge. However, we did identify other predictors including STAT score $\geq 3$, which may be potentially useful for conducting larger sample size studies and development of readmission risk prediction models. Postcardiac surgery AKI was also not associated with 1-year postdischarge hospital readmission. Therefore, reducing AKI postcardiac surgery would not likely result in reduced readmissions. These findings are consistent with our previous study among cardiac surgery patients that demonstrated no association between AKI and development of CKD and

TABLE 4. Associations (HR $[95 \%$ CI] $)$ between $\geq$ stage 1 AKI, $\geq$ stage 2 AKI, and increasing AKI stage with 30-day and 1-year readmission

\begin{tabular}{|c|c|c|c|c|c|c|}
\hline \multirow[b]{2}{*}{ AKI definitions } & \multicolumn{3}{|c|}{ 30-d readmission } & \multicolumn{3}{|c|}{ 1-y readmission } \\
\hline & n $(\%)$ & $\begin{array}{c}\text { Unadjusted } \\
\text { HR }(95 \% \text { CI })\end{array}$ & $\begin{array}{c}\text { Adjusted }{ }^{*} \\
\text { HR }(95 \% \text { CI })\end{array}$ & n $(\%)$ & $\begin{array}{c}\text { Unadjusted } \\
\text { HR }(95 \% \text { CI })\end{array}$ & $\begin{array}{c}\text { Adjusted } * \\
\text { HR }(95 \% \text { CI })\end{array}$ \\
\hline \multicolumn{7}{|l|}{ No AKI vs AKI } \\
\hline No AKI $(\mathrm{n}=223)$ & $13(6 \%)$ & 1.0 (ref) & 1.0 (ref) & $55(25 \%)$ & 1.0 (ref) & 1.0 (ref) \\
\hline$\geq$ Stage 1 AKI $(n=179)$ & $26(15 \%)$ & $1.86(0.92-3.76)$ & $1.57(0.72-3.41)$ & $61(34 \%)$ & $1.27(0.87-1.85)$ & $1.06(0.69-1.61)$ \\
\hline \multicolumn{7}{|l|}{ No/stage 1 AKI vs $\geq$ stage 2 AKI } \\
\hline No AKI/stage 1 AKI $(n=344)$ & $27(8 \%)$ & 1.0 (ref) & 1.0 (ref) & $93(27 \%)$ & $1.0(\mathrm{ref})$ & 1.0 (ref) \\
\hline$\geq$ Stage 2 AKI $(\mathrm{n}=58)$ & $12(21 \%)$ & $1.68(0.74-3.85)$ & $1.54(0.62-3.81)$ & $23(40 \%)$ & $1.21(0.73-2.01)$ & $0.98(0.55-1.74)$ \\
\hline \multicolumn{7}{|l|}{ Increasing AKI stage } \\
\hline No AKI $(\mathrm{n}=223)$ & $13(6 \%)$ & 1.0 (ref) & 1.0 (ref) & $55(25 \%)$ & 1.0 (ref) & 1.0 (ref) \\
\hline Stage 1 AKI $(n=121)$ & $14(12 \%)$ & $1.74(0.8-3.81)$ & $1.44(0.6-3.46)$ & $38(31 \%)$ & $1.25(0.82-1.9)$ & $1.07(0.68-1.69)$ \\
\hline Stage 2 AKI $(n=23)$ & $4(17 \%)$ & $2.23(0.66-7.51)$ & $2.1(0.6-7.29)$ & $8(35 \%)$ & $1.33(0.6-2.93)$ & $1.16(0.52-2.59)$ \\
\hline Stage 3 AKI $(n=35)$ & $8(23 \%)$ & $2.03(0.66-6.25)$ & $1.67(0.52-5.41)$ & $15(43 \%)$ & $1.31(0.69-2.49)$ & $0.91(0.42-1.97)$ \\
\hline
\end{tabular}

$A K I$, Acute kidney injury; $H R$, hazard ratio; $C I$, confidence interval; ref, reference group in the analysis. *Adjusted for age, STAT score $\geq 3$, CPB time $>120$ min, and cyanotic heart disease. 
TABLE 5. Mortality rate at 30 days and 1 year postcardiac surgery by AKI status and associations (HR [95\% CI]) between $\geq$ stage 1 AKI, $\geq$ stage 2 AKI, and increasing AKI stage with 30-day mortality

\begin{tabular}{|c|c|c|c|c|}
\hline \multirow[b]{2}{*}{ AKI definitions } & \multicolumn{3}{|c|}{ 30-d mortality } & \multirow{2}{*}{$\frac{1-y \text { mortality* }}{n(\%)}$} \\
\hline & n (\%) & Unadjusted HR (95\% CI) & Adjusted $\dagger$ HR (95\% CI) & \\
\hline \multicolumn{5}{|l|}{ No AKI vs AKI } \\
\hline No AKI $(n=223)$ & $0(0 \%)$ & 1.0 (ref) & 1.0 (ref) & $1(0.5 \%)$ \\
\hline$\geq$ Stage 1 AKI $(\mathrm{n}=179)$ & $7(3.9 \%)$ & NA & NA & $8(4.5)$ \\
\hline \multicolumn{5}{|c|}{ No/stage $1 \mathrm{AKI}$ vs stage $2 \mathrm{AKI}$ or greater } \\
\hline No AKI/stage 1 AKI $(\mathrm{n}=344)$ & $2(0.6 \%)$ & $1.0(\mathrm{ref})$ & 1.0 (ref) & $4(1.2 \%)$ \\
\hline$\geq$ Stage 2 AKI $(\mathrm{n}=58)$ & $5(8.6 \%)$ & $15.32(2.97-78.99)$ & $11.68(1.88-72.61) \ddagger$ & $5(8.6 \%)$ \\
\hline \multicolumn{5}{|l|}{ Increasing AKI stage } \\
\hline No AKI $(\mathrm{n}=223)$ & $0(0 \%)$ & 1.0 (ref) & NA & $1(0.5 \%)$ \\
\hline Stage 1 AKI $(\mathrm{n}=121)$ & $2(1.7 \%)$ & NA & NA & $3(2.5 \%)$ \\
\hline Stage 2 AKI $(n=23)$ & $1(4.4 \%)$ & NA & NA & $1(4.4 \%)$ \\
\hline Stage 3 AKI $(n=35)$ & $4(11.4 \%)$ & NA & NA & $4(11.4 \%)$ \\
\hline
\end{tabular}

$A K I$, Acute kidney injury; $H R$, hazard ratio; $C I$, confidence interval; ref, reference group in the analysis; $N A$, not applicable. $*$ Total deaths from 0 to 365 days postcardiac surgery discharge. $\dagger$ Adjusted for age, STAT score $\geq 3$, CPB time $>120 \mathrm{~min}$, and cyanotic heart disease. $\ddagger$ Adjusted and statistically significant at $P<.05$.

hypertension 5 years postdischarge; however, this remains an area of controversy. ${ }^{21}$ In noncardiac surgery children admitted to the intensive care unit, AKI has been shown to be associated with increased health care use, including postdischarge hospitalizations, physician visits, and other important health outcomes. ${ }^{8,22,23}$ Therefore, given the known strong association of AKI with readmission and other outcomes in non-cardiac surgery populations, these findings are
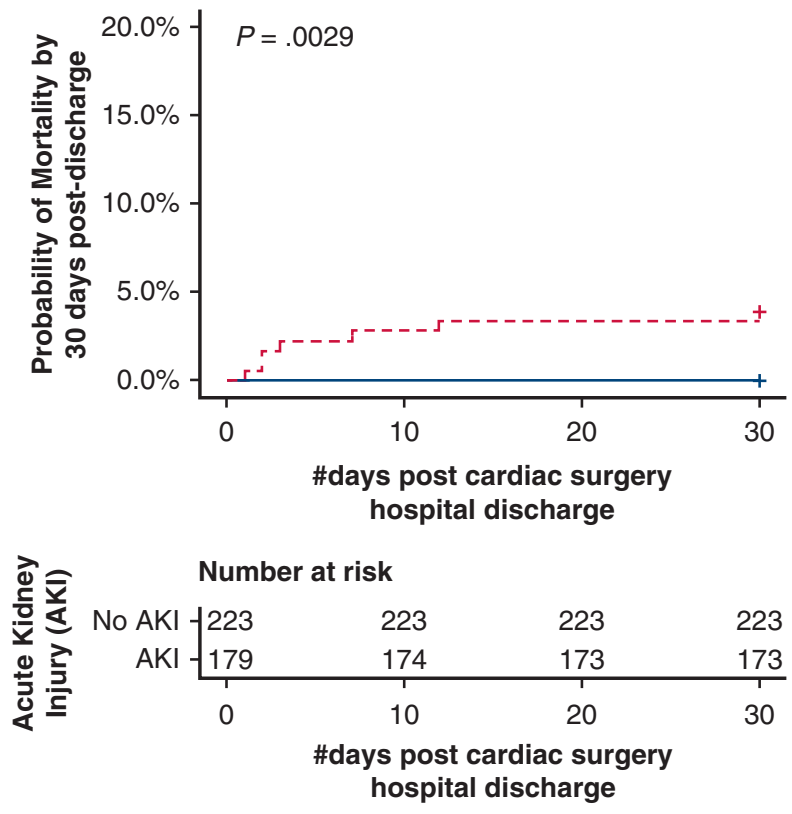

Acute Kidney Injury $(\mathrm{AKI})+\mathrm{No} A K I+\mathrm{AKI}$

FIGURE 3. Kaplan-Meier curves for mortality within 30 days by AKI status. The dotted red line represents patients with postoperative AKI and the blue line represents patients without postoperative AKI. There is a statistically significant difference between the two survival curves (logrank test $P=.0029)$. AKI, Acute kidney injury. notable. Children undergoing cardiac surgery are at high risk of readmission, which prompts an urgent need to find easily identifiable, strong predictors that would allow for targeted interventions to reduce readmission. The high proportion of readmissions along with the lack of association between AKI and readmission calls on future research to identify other risk factors for readmission after cardiac surgery discharge. Previously identified 30-day risk factors should be further investigated at 1 year and may include sociodemographic risk factors (ethnicity) and clinical risk factors (complications during admission). ${ }^{19,20}$ In a 30-day

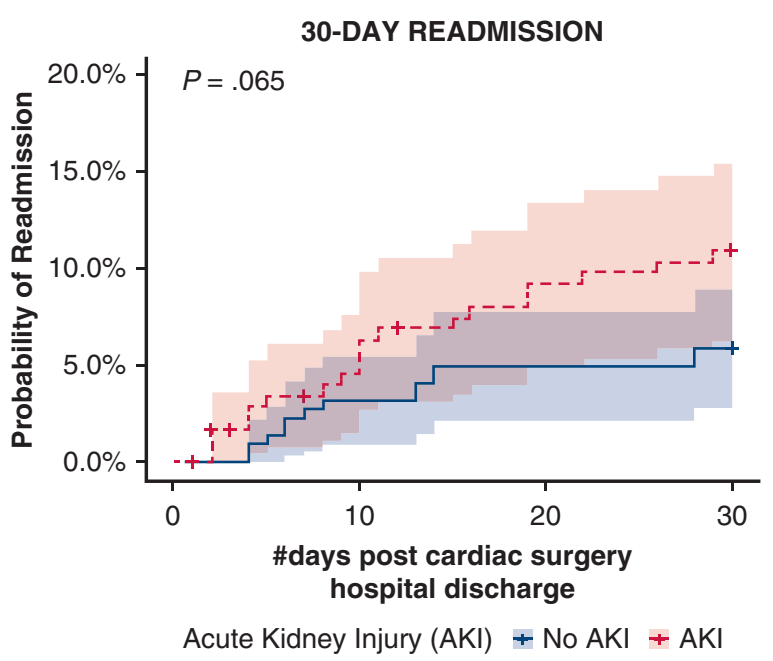

FIGURE 4. Kaplan-Meier curves for readmission within 30 days by AKI status. The dotted red line represents patients with postoperative AKI and the blue line represents patients without post-operative AKI. The red-and blue-shaded areas represent the confidence intervals for the AKI and nonAKI group, respectively. There is no statistically significant difference between the 2 survival curves (log-rank test $P=.065)$. AKI, Acute kidney injury. 
readmission study, Benavidez and colleagues ${ }^{20}$ found that vulnerable populations such as Hispanic children and those on public insurance were more likely to be readmitted after pediatric cardiac surgery. Clinical risk factors such as complications during admission for pediatric cardiac surgery are associated with poor clinical outcomes such as increased length of stay, resource use, and inpatient death during hospital index admission. ${ }^{24}$ However, these associations have yet to be assessed in long term (1-year readmission) studies.

We found that children with $\geq$ stage 2 AKI were at greater risk for mortality 30 days after cardiac surgery discharge. It was not possible to assess the association between AKI and 1-year mortality as there were only 2 deaths between 30 days and 365 days postcardiac surgery. Therefore, larger samples ( $>400$ children) are required to better understand AKI's association with mortality. The current study's results are congruent with a single-center study of 718 children where RIFLE (Pediatric Risk, Injury, Failure, Loss, End Stage Renal Disease) stage F (most comparable with stage 3 AKI defined using Kidney Disease: Improving Global Outcomes) was associated with greater long-term mortality (median follow-up of 4 years). ${ }^{25}$ However, to our knowledge, no study has assessed the adjusted association between AKI and mortality at 30 days post-pediatric cardiac surgery, a clinically relevant time point. In addition, we are aware of only 4 papers (including the study mentioned previously) that have studied this relationship beyond 30 days. ${ }^{2,25-27}$ Of these, one study focused solely on neonates and the remaining three were single centre studies and did not report on the association of AKI with 30-day mortality. Further research and development of care guidelines are warranted to improve peri and postoperative mortality.

Findings must be considered within the study's context. Limitations of the study include lack of information regarding zip-code/postal code or nature of practice (local vs distant referral), resulting in loss of readmission information from hospitals other than our centres and potentially information bias in outcome ascertainment. However, the 30-day outcome is a relatively short-term postdischarge outcome, during which time close follow-up at the centre performing the index cardiac surgery was highly likely. There was also intersite and interphysician variability in discharge criteria. Also, limited data were available regarding specific reasons for readmission and mortality, including whether readmissions for cardiac procedures were planned procedures. We were also limited in terms of the cyanotic heart disease designation and were unable to control for postdischarge variables such as new comorbidities or treatments due to limitations of collected data. The strengths of this study include the large prospective design with detailed index and readmission information up to a year postdischarge.
In conclusion, children with severe AKI ( $\geq$ stage 2 ) after cardiac surgery are at a greater risk for mortality, but not readmission, within 30 days of discharge, compared with children without AKI. Future research should evaluate new factors that may predict readmission after pediatric cardiac surgery and interventions to reduce short-term mortality risk in children after cardiac surgery.

\section{Conflict of Interest Statement}

Dr Parikh receives consulting fees from Akebia Therapeutics, Inc, Genfit Biopharmaceutical Company, and Renaltix AI. All other authors reported no conflicts of interest.

The Journal policy requires editors and reviewers to disclose conflicts of interest and to decline handling or reviewing manuscripts for which they may have a conflict of interest. The editors and reviewers of this article have no conflicts of interest.

\section{References}

1. Li S, Krawczeski CD, Zappitelli M, Devarajan P, Thiessen-Philbrook H, Coca SG, et al. Incidence, risk factors, and outcomes of acute kidney injury after pediatric cardiac surgery: a prospective multicenter study*. Crit Care Med. 2011; 39:1493-9.

2. Morgan CJ, Zappitelli M, Robertson CMT, Alton GY, Sauve RS, Joffe AR, et al. Risk factors for and outcomes of acute kidney injury in neonates undergoing complex cardiac surgery. J Pediatr. 2013;162:120-7.e1.

3. Brown JR, Hisey WM, Marshall EJ, Likosky DS, Nichols EL, Everett AD, et al. Acute kidney injury severity and long-term readmission and mortality following cardiac surgery. Ann Thorac Surg. 2016;102:1482-9.

4. Horkan CM, Purtle SW, Mendu ML, Moromizato T, Gibbons FK, Christopher KB. The association of acute kidney injury in the critically ill and postdischarge outcomes: a cohort study*. Crit Care Med. 2015;43:354-64.

5. Koulouridis I, Price LL, Madias NE, Jaber BL. Hospital-acquired acute kidney injury and hospital readmission: a cohort study. Am J Kidney Dis. 2015;65:275-82.

6. Brown JR, Malenka DJ, DeVries JT, Robb JF, Jayne JE, Friedman BJ, et al. Transient and persistent renal dysfunction are predictors of survival after percutaneous coronary intervention: insights from the Dartmouth dynamic registry. Catheter Cardiovasc Interv. 2008;72:347-54.

7. Ishani A, Nelson D, Clothier B, Schult T, Nugent S, Greer N, et al. The magnitude of acute serum creatinine increase after cardiac surgery and the risk of chronic kidney disease, progression of kidney disease, and death. Arch Intern Med. 2011;171:226-33.

8. Hessey E, Morissette G, Lacroix J, Perreault S, Samuel S, Dorais M, et al. Healthcare utilization after acute kidney injury in the pediatric intensive care unit. Clin J Am Soc Nephrol. 2018;13:685-92.

9. Mammen C, Al Abbas A, Skippen P, Nadel H, Levine D, Collet JP, et al. Longterm risk of CKD in children surviving episodes of acute kidney injury in the intensive care unit: a prospective cohort study. Am J Kidney Dis. 2012;59:523-30.

10. Lee SA, Cozzi M, Bush EL, Rabb H. Distant organ dysfunction in acute kidney injury: a review. Am J Kidney Dis. 2018;72:846-56.

11. Faubel S, Edelstein CL. Mechanisms and mediators of lung injury after acute kidney injury. Nat Rev Nephrol. 2016;12:48-60.

12. Kogon B, Jain A, Oster M, Woodall K, Kanter K, Kirshbom P. Risk factors associated with readmission after pediatric cardiothoracic surgery. Ann Thorac Surg. 2012;94:865-73.

13. Saharan S, Legg AT, Armsby LB, Zubair MM, Reed RD, Langley SM. Causes of readmission after operation for congenital heart disease. Ann Thorac Surg. 2014; 98:1667-73.

14. Greenberg JH, Zappitelli M, Jia Y, Thiessen-Philbrook HR, de Fontnouvelle CA, Wilson FP, et al. Biomarkers of AKI progression after pediatric cardiac surgery. $J$ Am Soc Nephrol. 2018;29:1549-56.

15. Jenkins KJ, Gauvreau K, Newburger JW, Spray TL, Moller JH, Iezzoni LI. Consensus-based method for risk adjustment for surgery for congenital heart disease. J Thorac Cardiovasc Surg. 2002;123:110-8. 
16. Levey AS, Eckardt K-U, Tsukamoto Y, Levin A, Coresh J, Rossert J, et al. Definition and classification of chronic kidney disease: a position statement from kidney disease: improving global outcomes (KDIGO). Kidney Int. 2005;67: 2089-100.

17. U.S. Centers for Medicare \& Medicaid Services. Hospital Readmissions Reduction Program (HRRP); 2019. Available at: https://www.cms.gov/Medicare/Med icare-Fee-for-Service-Payment/AcuteInpatientPPS/Readmissions-Reduction-Pr ogram.html. Accessed October 3, 2019.

18. Government of Ontario, Ministry of Health, Ministry of Long-Term Care. Excellent care for all - health care professionals - MOHLTC. Available at: http://www. health.gov.on.ca/en/pro/programs/ecfa/legislation/act.aspx. Accessed October 3, 2019.

19. Kogon BE, Oster ME, Wallace A, Chiswell K, Hill KD, Cox ML, et al. Readmission following pediatric cardiothoracic surgery: an analysis of the Society of Thoracic Surgeons database. Ann Thorac Surg. 2019;107: 1816-23.

20. Benavidez OJ, He W, Lahoud-Rahme M. Readmissions following congenital heart surgery in infants and children. Pediatr Cardiol. 2019;40: 994-1000.

21. Greenberg JH, Zappitelli M, Devarajan P, Thiessen-Philbrook HR, Krawczeski C, Li S, et al. Kidney outcomes 5 years after pediatric cardiac surgery: the TRIBEAKI study. JAMA Pediatr. 2016;170:1071-8.
22. Hessey E, Morissette G, Lacroix J, Perreault S, Samuel S, Dorais M, et al. Long-term mortality after acute kidney injury in the pediatric ICU. Hosp Pediatr. 2018;8:260-8.

23. Hessey E, Perreault S, Dorais M, Roy L, Zappitelli M. Acute kidney injury in crit ically ill children and subsequent chronic kidney disease. Can J Kidney Health Dis. 2019;6:2054358119880188.

24. Benavidez OJ, Connor JA, Gauvreau K, Jenkins KJ. The contribution of complications to high resource utilization during congenital heart surgery admissions Congenit Heart Dis. 2007;2:319-26.

25. Watkins SC, Williamson K, Davidson M, Donahue BS. Long-term mortality associated with acute kidney injury in children following congenital cardiac surgery. Paediatr Anaesth. 2014;24:919-26.

26. Hirano D, Ito A, Yamada A, Kakegawa D, Miwa S, Umeda C, et al. Independent risk factors and 2-year outcomes of acute kidney injury after surgery for congenital heart disease. Am J Nephrol. 2017;46:204-9.

27. Park S-K, Hur M, Kim E, Kim WH, Park JB, Kim Y, et al. Risk factors for acute kidney injury after congenital cardiac surgery in infants and children: a retrospective observational study. PLoS One. 2016;11:e0166328.

Key Words: acute kidney injury, pediatric cardiac surgery, readmission, mortality, postdischarge outcomes 


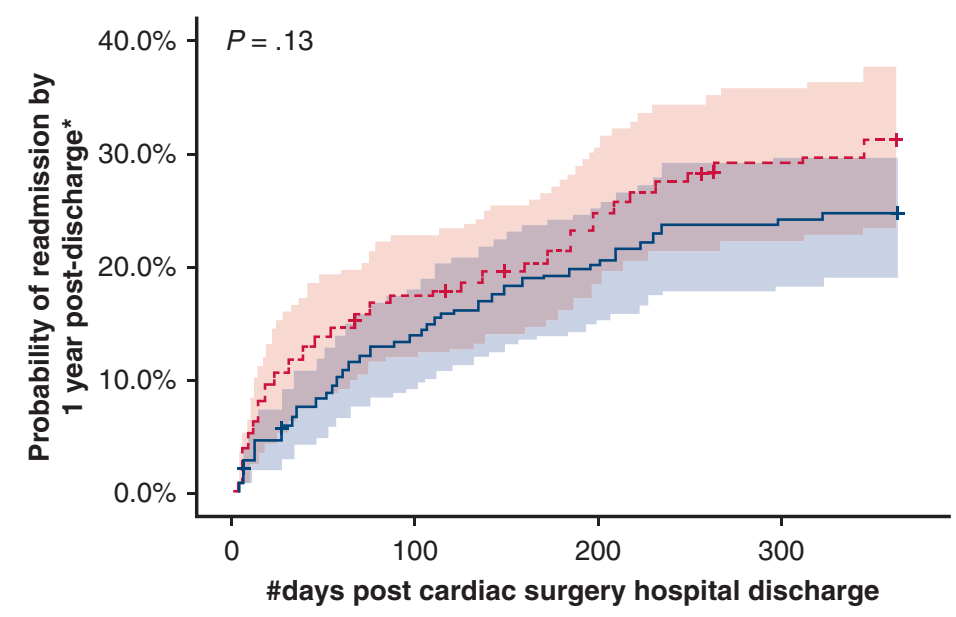

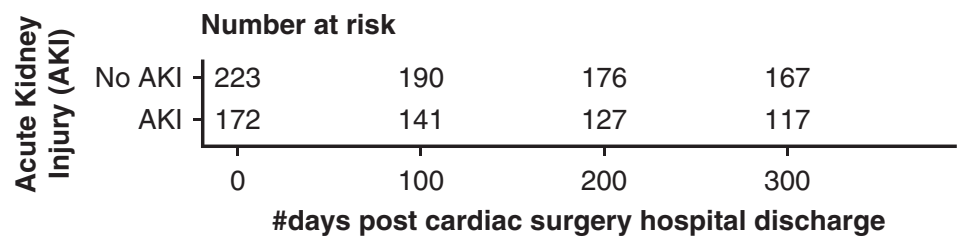

*in patients alive at 30 days post-discharge

$$
\text { Acute Kidney Injury (AKI) + No AKI + AKI }
$$

APPENDIX FIGURE 1. Kaplan-Meier curve for 1-year readmission postcardiac surgery discharge in patients alive at 30 days only, by AKI status. Shown is a survival curve for the outcome of readmission within 1 year of cardiac surgery discharge by AKI versus no AKI status in patients alive at 30 days. The red dotted line represents patients with postoperative AKI and the blue line represents patients without post-operative AKI. The red-and blue-shaded areas represent the confidence intervals for the AKI and non-AKI group, respectively. There is no statistically significant difference between the 2 survival curves (log-rank test $P=.13$ ). AKI, Acute kidney injury. 
APPENDIX TABLE 1. Patient characteristics by AKI status

\begin{tabular}{|c|c|c|c|c|}
\hline \multirow[b]{2}{*}{ Patient characteristics } & \multicolumn{4}{|c|}{ Number (\%), mean (SD) or median (IQR) } \\
\hline & Total, $n=402$ & Non-AKI, $n=223$ & AKI, $n=179$ & $P$ value \\
\hline \multicolumn{5}{|l|}{ Preoperative/baseline variables } \\
\hline Age, y & $1.8(0.4,5.2)$ & $3.6(0.5,7.3)$ & $0.7(0.4,3.7)$ & $<.001$ \\
\hline \multicolumn{5}{|l|}{ Age } \\
\hline $31 \mathrm{~d}$ to $1 \mathrm{y}$ & $179(45 \%)$ & $78(35 \%)$ & $101(56 \%)$ & $<.001$ \\
\hline$>1$ to $<18 \mathrm{y}$ & $223(55 \%)$ & $145(65 \%)$ & $78(44 \%)$ & \\
\hline Female sex & $192(48 \%)$ & $106(48 \%)$ & $86(48 \%)$ & .919 \\
\hline Previous cardiothoracic operations & $165(42 \%)$ & $87(40 \%)$ & $78(44 \%)$ & .405 \\
\hline Cyanotic heart disease & $134(35 \%)$ & $86(32 \%)$ & $48(44 \%)$ & $<.001$ \\
\hline \multicolumn{5}{|l|}{ Surgery-related variables } \\
\hline \multicolumn{5}{|l|}{ STAT category (dichotomized) } \\
\hline$<3$ & $359(90 \%)$ & $210(95 \%)$ & $149(84 \%)$ & $<.001$ \\
\hline$\geq 3$ & $41(10 \%)$ & $12(5 \%)$ & $29(16 \%)$ & \\
\hline \multicolumn{5}{|l|}{ Surgery type } \\
\hline Septal defect repair & $134(35 \%)$ & $98(36 \%)$ & $36(33 \%)$ & .004 \\
\hline Inflow/outflow tract or valve procedure & $62(16 \%)$ & $48(18 \%)$ & $14(13 \%)$ & \\
\hline Combined procedure & $184(48 \%)$ & $124(46 \%)$ & $60(55 \%)$ & \\
\hline \multicolumn{5}{|l|}{ Urgency of surgery } \\
\hline Elective & $368(92 \%)$ & $265(93 \%)$ & $103(89 \%)$ & .302 \\
\hline Urgent & $34(8 \%)$ & $21(7 \%)$ & $13(11 \%)$ & \\
\hline CPB time, $\min$ & $105.78(60.01)$ & $93.85(52.51)$ & $120.65(65.37)$ & $<.001$ \\
\hline CPB time $>120 \mathrm{~min}$ & $126(31 \%)$ & $126(31 \%)$ & $50(22 \%)$ & $<.001$ \\
\hline Crossclamp time, $\min$ & $45.85(44.08)$ & $43.85(42.35)$ & $48.34(46.14)$ & .450 \\
\hline \multicolumn{5}{|l|}{ Postoperative variables } \\
\hline Length of ICU stay, d & $2(1,4)$ & $2(1,3)$ & $3(2,6)$ & $<.001$ \\
\hline Length of hospital stay, $d$ & $5(4,9)$ & $4(3,6)$ & $7(5,13)$ & $<.001$ \\
\hline
\end{tabular}


APPENDIX TABLE 2. Patient characteristics by mortality at 1-year postcardiac surgery

\begin{tabular}{|c|c|c|c|c|}
\hline \multirow[b]{2}{*}{ Patient characteristics } & \multicolumn{4}{|c|}{ Number (\%), mean (SD) or median (IQR) } \\
\hline & Total $(N=402)$ & No mortality within 1 y $(N=393)$ & Mortality within 1 y $(N=9)$ & $P$ value \\
\hline \multicolumn{5}{|l|}{ Preoperative/baseline variables } \\
\hline Age, y & $1.8(0.44,5.23)$ & $1.71(0.44,5.05)$ & $8.54(0.66,13.88)$ & .115 \\
\hline \multicolumn{5}{|l|}{ Age } \\
\hline $31 \mathrm{~d}$ to $1 \mathrm{y}$ & $179(45 \%)$ & $176(45 \%)$ & $3(33 \%)$ & \\
\hline$>1$ to $<18 \mathrm{y}$ & $223(55 \%)$ & $217(55 \%)$ & $6(67 \%)$ & .494 \\
\hline Female sex & $192(48 \%)$ & $187(48 \%)$ & $5(56 \%)$ & .636 \\
\hline Previous cardiothoracic operations & $165(42 \%)$ & $160(41 \%)$ & $5(56 \%)$ & .396 \\
\hline Cyanotic heart disease & $134(35 \%)$ & $129(35 \%)$ & $5(56 \%)$ & .202 \\
\hline Noncardiac abnormalities & $101(26 \%)$ & $96(25 \%)$ & $5(56 \%)$ & .037 \\
\hline \multicolumn{5}{|l|}{ Surgery-related variables } \\
\hline STAT score $<3$ & $359(90 \%)$ & $354(91 \%)$ & $5(56 \%)$ & $<.001$ \\
\hline STAT score $\geq 3$ & $41(10 \%)$ & $37(9 \%)$ & $4(44 \%)$ & \\
\hline \multicolumn{5}{|l|}{ Surgery type } \\
\hline Septal defect repair & $134(35 \%)$ & $134(36 \%)$ & $0(0 \%)$ & .038 \\
\hline Inflow/outflow tract or valve procedure & $62(16 \%)$ & $61(16 \%)$ & $1(11 \%)$ & \\
\hline Combined procedure & $184(48 \%)$ & $176(47 \%)$ & $8(89 \%)$ & \\
\hline \multicolumn{5}{|l|}{ Urgency of surgery } \\
\hline Elective & $368(92 \%)$ & $361(92 \%)$ & $7(78 \%)$ & .133 \\
\hline Urgent & $34(8 \%)$ & $32(8 \%)$ & $2(22 \%)$ & \\
\hline $\mathrm{CPB}$ time, $\min$ & 105.78 & $103.76(56.55)$ & $194.11(121.8)$ & .013 \\
\hline $\mathrm{CPB}$ time $>120 \mathrm{~min}$ & $126(31 \%)$ & $119(30 \%)$ & $7(78 \%)$ & .002 \\
\hline Crossclamp time, $\min$ & $45.85(44.08)$ & $45.72(43.78)$ & $51.44(58.72)$ & .995 \\
\hline \multicolumn{5}{|l|}{ Postoperative variables } \\
\hline Length of ICU stay, d & $2(1,4)$ & $2(1,4)$ & $9.5(2,35.5)$ & .023 \\
\hline Length of hospital stay, d & $5(4,9)$ & $5(4,9)$ & $7(2,31)$ & .851 \\
\hline \multicolumn{5}{|l|}{ KDIGO AKI stages } \\
\hline No AKI & $223(55 \%)$ & $222(56 \%)$ & $1(11 \%)$ & $<.001$ \\
\hline Stage $1 \mathrm{AKI}$ & $121(30 \%)$ & $118(30 \%)$ & $3(33 \%)$ & \\
\hline Stage 2 AKI & $23(6 \%)$ & $22(6 \%)$ & $1(11 \%)$ & \\
\hline Stage 3 AKI & $35(9 \%)$ & $31(8 \%)$ & $4(44 \%)$ & \\
\hline
\end{tabular}

Categorical variables are reported as $\mathrm{n}(\%)$ and continuous variables are reported as mean (SD) or median (IQR). SD, Standard deviation; IQR, interquartile range; $S T A T$, The Society of Thoracic Surgeons-European Association for Cardio-Thoracic Surgery risk adjustment tool; $C P B$, cardiopulmonary bypass; $I C U$, intensive care unit; KDIGO, Kidney Disease: Improving Global Outcomes; $A K I$, acute kidney injury. 
APPENDIX TABLE 3. Primary reasons for readmission 1-year postcardiac surgery discharge by AKI status

\begin{tabular}{|c|c|c|c|}
\hline Reason for readmission* & Total, $\mathbf{n}=113$ & Non-AKI patients, $n=55$ & AKI patients, $\mathbf{n}=\mathbf{5 8}$ \\
\hline Neurologic & $3(3 \%)$ & $2(4 \%)$ & $1(2 \%)$ \\
\hline Seizure & $2(1.77)$ & $1(1.82)$ & $1(1.72)$ \\
\hline Unspecified & $1(0.88)$ & $1(1.82)$ & 0 \\
\hline Gastrointestinal & $11(9 \%)$ & $4(7 \%)$ & $7(11 \%)$ \\
\hline Gastroenteritis & $2(1.77)$ & 0 & $2(3.45)$ \\
\hline Gastrostomy & $1(0.88)$ & 0 & $1(1.72)$ \\
\hline EGD & $1(0.88)$ & $1(1.82)$ & 0 \\
\hline Bloody stool & $1(0.88)$ & 0 & $1(1.72)$ \\
\hline Ultrasound of the abdomen & $1(0.88)$ & 0 & $1(1.72)$ \\
\hline Failure to thrive & $1(0.88)$ & $1(1.82)$ & 0 \\
\hline Gastronomy tube & $2(1.77)$ & 0 & $2(3.45)$ \\
\hline Nausea & $1(0.88)$ & $1(1.82)$ & 0 \\
\hline Unspecified & $1(0.88)$ & $1(1.82)$ & 0 \\
\hline Respiratory (noninfectious) & $12(10 \%)$ & $6(11 \%)$ & $6(10 \%)$ \\
\hline Pleural effusion & $3(2.65)$ & $1(1.82)$ & $2(3.45)$ \\
\hline Pneumonectomy & $1(0.88)$ & $1(1.82)$ & 0 \\
\hline Respiratory failure & $1(0.88)$ & $1(1.82)$ & 0 \\
\hline Chest tube placement & $1(0.88)$ & $1(1.82)$ & 0 \\
\hline Chest radiograph & $1(0.88)$ & $1(1.82)$ & 0 \\
\hline Cough & $1(0.88)$ & $1(1.82)$ & 0 \\
\hline Tracheomalacia & $1(0.88)$ & $1(1.82)$ & 0 \\
\hline Unspecified & $4(3.54)$ & 0 & $4(6.90)$ \\
\hline Cardiac issue or procedure & $33(28 \%)$ & $14(25 \%)$ & $19(31 \%)$ \\
\hline Arrhythmia & $4(3.54)$ & $1(1.82)$ & $3(5.17)$ \\
\hline Hypoplastic heart & $1(0.88)$ & 0 & $1(1.72)$ \\
\hline Pacemaker placement & $1(0.88)$ & 0 & $1(1.72)$ \\
\hline Heart failure & $1(0.88)$ & 0 & $1(1.72)$ \\
\hline Endocarditis & $2(1.77)$ & $1(1.82)$ & $1(1.72)$ \\
\hline Computed tomography angiogram & $1(0.88)$ & 0 & $1(1.72)$ \\
\hline Cardiac catheterization & $11(9.73)$ & $6(10.91)$ & $5(8.62)$ \\
\hline Echocardiogram & $1(0.88)$ & 0 & $1(1.72)$ \\
\hline Cardiac surgical repair & $4(3.54)$ & $3(5.45)$ & $1(1.72)$ \\
\hline Pulmonary artery anomaly & $1(0.88)$ & 0 & $1(1.72)$ \\
\hline Pulmonary artery stenosis & $2(1.77)$ & $2(3.64)$ & 0 \\
\hline Pericardial effusion & $2(1.77)$ & $1(1.82)$ & $1(1.72)$ \\
\hline Not specified & $2(1.77)$ & 0 & $2(3.45)$ \\
\hline Renal (noninfectious) & $1(1 \%)$ & $1(2 \%)$ & $0(0 \%)$ \\
\hline Ureteral pelvic junction obstruction & $1(0.88)$ & $1(1.82)$ & 0 \\
\hline Ear, nose, throat & $12(10 \%)$ & $9(16 \%)$ & $3(5 \%)$ \\
\hline Otitis media myringotomy, tube placement in ears & $5(4.42)$ & $5(9.09)$ & 0 \\
\hline Larynx stenosis & $1(0.88)$ & 0 & $1(1.72)$ \\
\hline Nasolacrimal duct obstruction/probing & $2(1.77)$ & $1(1.82)$ & $1(1.72)$ \\
\hline Adenoidectomy & $1(0.88)$ & $1(1.82)$ & 0 \\
\hline Cleft palate & $1(0.88)$ & 0 & $1(1.72)$ \\
\hline Micro laryngoscopy & $1(0.88)$ & $1(1.82)$ & 0 \\
\hline Infectious (non-gastroenteritis) & $12(10 \%)$ & $5(9 \%)$ & $7(11 \%)$ \\
\hline Respiratory infection & $8(7.08)$ & $3(5.45)$ & $5(8.62)$ \\
\hline Fever & $1(0.88)$ & 0 & $1(1.72)$ \\
\hline UTI & $1(0.88)$ & $1(1.82)$ & 0 \\
\hline Skin infection & $1(0.88)$ & $1(1.82)$ & 0 \\
\hline Unspecified & $1(0.88)$ & 0 & $1(1.72)$ \\
\hline Other & $29(26 \%)$ & $14(25 \%)$ & $15(26 \%)$ \\
\hline
\end{tabular}

Categorical variables are reported as n (\%). AKI, Acute kidney injury; EGD, esophagogastroduodenoscopy; UTI, urinary tract infection. *Primary reason for readmission was collected retrospectively during collection of the primary outcome. At the time of analysis, these were categorized (authors S.N. and H.T.P.) and then adjudicated (author M.Z.). 
APPENDIX TABLE 4. Associations (HR [95\% CI]) between covariates and readmission postcardiac surgery discharge (full models)

\begin{tabular}{|c|c|c|}
\hline AKI definitions & $\frac{\text { 30-d readmission }}{\text { Adjusted }^{*} \text { HR }(95 \% \text { CI })}$ & $\frac{\text { 1-y readmission }}{\text { Adjusted }^{*} \text { HR }(95 \% \text { CI })}$ \\
\hline \multicolumn{3}{|l|}{ No AKI vs AKI } \\
\hline No AKI $(\mathrm{n}=223)$ & 1.0 (ref) & 1.0 (ref) \\
\hline$\geq$ Stage 1 AKI $(\mathrm{n}=179)$ & $1.57(0.72-3.41)$ & $1.06(0.69-1.61)$ \\
\hline Age & $1.03(0.94-1.12)$ & $0.97(0.91-1.03)$ \\
\hline STAT surgical severity score $\geq 3$ & $0.75(0.23-2.5)$ & $2(1.17-3.43) \dagger$ \\
\hline $\mathrm{CPB}$ time $>120 \mathrm{~min}$ & $1.29(0.62-2.66)$ & $1.01(0.64-1.58)$ \\
\hline Cyanotic heart disease & $0.49(0.22-1.08)$ & $0.73(0.47-1.12)$ \\
\hline \multicolumn{3}{|l|}{ No/stage 1 AKI vs $\geq$ stage 2 AKI } \\
\hline No AKI/stage 1 AKI $(\mathrm{n}=344)$ & 1.0 (ref) & 1.0 (ref) \\
\hline$\geq$ Stage 2 AKI $(\mathrm{n}=58)$ & $1.54(0.62-3.81)$ & $0.98(0.55-1.74)$ \\
\hline Age & $1.02(0.94-1.11)$ & $0.97(0.91-1.03)$ \\
\hline STAT surgical severity score $\geq 3$ & $0.78(0.23-2.65)$ & $2.02(1.17-3.46) \dagger$ \\
\hline CPB time $>120 \mathrm{~min}$ & $1.24(0.57-2.67)$ & $1.02(0.64-1.64)$ \\
\hline Cyanotic heart disease & $0.46(0.21-1.01)$ & $0.72(0.47-1.1)$ \\
\hline \multicolumn{3}{|l|}{ Increasing AKI stage } \\
\hline No AKI $(\mathrm{n}=223)$ & 1.0 (ref) & 1.0 (ref) \\
\hline Stage 1 AKI $(\mathrm{n}=121)$ & $1.44(0.6-3.46)$ & $1.07(0.68-1.69)$ \\
\hline Stage 2 AKI $(n=23)$ & $2.1(0.6-7.29)$ & $1.16(0.52-2.59)$ \\
\hline Stage 3 AKI $(\mathrm{n}=35)$ & $1.67(0.52-5.41)$ & $0.91(0.42-1.97)$ \\
\hline Age & $1.03(0.94-1.12)$ & $0.97(0.91-1.03)$ \\
\hline STAT surgical severity score $\geq 3$ & $0.76(0.23-2.52)$ & $2.01(1.17-3.43) \dagger$ \\
\hline $\mathrm{CPB}$ time $>120 \mathrm{~min}$ & $1.24(0.59-2.6)$ & $1.03(0.65-1.66)$ \\
\hline Cyanotic heart disease & $0.49(0.22-1.08)$ & $0.72(0.47-1.12)$ \\
\hline
\end{tabular}

$\overline{H R}$, Hazard ratio; $C I$, confidence interval; $A K I$, acute kidney injury; ref, reference group in the analysis; STAT, The Society of Thoracic Surgeons-European Association for Cardio-Thoracic Surgery risk adjustment tool; $C P B$, cardiopulmonary bypass. *Adjusted for age, STAT surgical severity score $\geq 3, \mathrm{CPB}$ time $>120$ min. $\dagger$ Adjusted and statistically significant at $P<.05$.

APPENDIX TABLE 5. Associations (HR [95\% CI]) between $\geq$ stage 1 AKI, $\geq$ stage 2 AKI, and increasing AKI stage with 1-year readmission in patients alive at 30 days postcardiac surgery discharge

\begin{tabular}{lccc}
\hline & \multicolumn{3}{c}{ 1-y readmission } \\
\cline { 2 - 4 } AKI definitions & $\mathbf{n ~ ( \% )}$ & Unadjusted HR (95\% CI) & Adjusted* HR (95\% CI) \\
\hline No AKI vs AKI & & $1.0(\mathrm{ref})$ & $1.0(\mathrm{ref})$ \\
$\quad$ No AKI & $55(25 \%)$ & $1.33(0.92-1.94)$ & $1.11(0.73-1.69)$ \\
$\quad \geq$ Stage 1 AKI & $54(31 \%)$ & & $1.0(\mathrm{ref})$ \\
Increasing AKI stage & & $1.0(\mathrm{ref})$ & $1.08(0.62-1.9)$ \\
$\quad$ No/stage 1 AKI & $91(27 \%)$ & $1.34(0.81-2.22)$ & \\
$\geq$ Stage 2 AKI & $18(34 \%)$ & & \\
\hline
\end{tabular}

$H R$, Hazard ratio; $C I$, confidence interval; $A K I$, acute kidney injury; ref, reference group in the analysis; $N A$, not applicable. *Adjusted for age, STAT score $\geq 3$, CPB time $>120$ minutes and cyanotic heart disease. 
APPENDIX TABLE 6. Associations (HR [95\% CI]) between covariates and mortality postcardiac surgery discharge (full models)

\begin{tabular}{|c|c|c|}
\hline AKI definitions & $\frac{\text { 30-d mortality }}{\text { Adjusted }^{*} \text { HR }(95 \% \text { CI })}$ & $\frac{\text { 1-y mortality }}{\text { Adjusted }^{*} \text { HR }(95 \% \text { CI })}$ \\
\hline \multicolumn{3}{|l|}{ No AKI vs AKI } \\
\hline No AKI $(\mathrm{n}=223)$ & 1.0 (ref) & 1.0 (ref) \\
\hline$\geq$ Stage 1 AKI $(\mathrm{n}=179)$ & NA & $6.73(0.74-61.42)$ \\
\hline Age & $1.18(1.05-1.33) \dagger$ & $1.18(1.06-1.31) \dagger$ \\
\hline STAT surgical severity score $\geq 3$ & $1.41(0.23-8.51)$ & $1.88(0.39-9.1)$ \\
\hline CPB time $>120 \mathrm{~min}$ & $7.67(0.87-67.53)$ & $4.51(0.86-23.71)$ \\
\hline Cyanotic heart disease & $1.2(0.24-5.86)$ & $0.57(0.13-2.44)$ \\
\hline \multicolumn{3}{|l|}{ No/stage 1 AKI vs $\geq$ stage 2} \\
\hline No AKI/stage 1 AKI $(n=344)$ & 1.0 (ref) & 1.0 (ref) \\
\hline$\geq$ Stage 2 AKI $(\mathrm{n}=58)$ & $11.68(1.88-72.61) \dagger$ & $4.5(1-20.39) \dagger$ \\
\hline Age & $1.16(1.04-1.29) \dagger$ & $1.17(1.06-1.29) \dagger$ \\
\hline STAT surgical severity score $\geq 3$ & $3.28(0.51-21.01)$ & $2.96(0.61-14.32)$ \\
\hline CPB time $>120 \mathrm{~min}$ & $6.41(0.68-60.11)$ & $3.88(0.69-21.71)$ \\
\hline Cyanotic heart disease & $2.4(0.36-16.16)$ & $0.74(0.14-3.76)$ \\
\hline \multicolumn{3}{|l|}{ Increasing AKI stage } \\
\hline No AKI $(\mathrm{n}=223)$ & NA & 1.0 (ref) \\
\hline Stage 1 AKI $(n=121)$ & NA & $4.61(0.43-49.42)$ \\
\hline Stage 2 AKI $(n=23)$ & NA & $10.05(0.61-165.5)$ \\
\hline Stage 3 AKI $(\mathrm{n}=35)$ & NA & $13.56(1.07-172.24) \dagger$ \\
\hline Age & $1.17(1.05-1.31) \dagger$ & $1.18(1.06-1.3) \dagger$ \\
\hline STAT surgical severity score $\geq 3$ & $1.91(0.28-12.89)$ & $2.12(0.41-10.91)$ \\
\hline CPB time $>120 \mathrm{~min}$ & $4.77(0.46-49.73)$ & $3.43(0.58-20.17)$ \\
\hline Cyanotic heart disease & $2.28(0.37-13.86)$ & $0.8(0.17-3.85)$ \\
\hline
\end{tabular}

$H R$, Hazard ratio; $C I$, confidence interval; $A K I$, acute kidney injury; ref, reference group in the analysis; STAT, The Society of Thoracic Surgeons-European Association for Cardio-Thoracic Surgery risk adjustment tool; $C P B$, cardiopulmonary bypass; $N A$, not applicable. *Adjusted for age, STAT surgical severity score $\geq 3$, CPB time $>120$ minutes. $\dagger$ Adjusted and statistically significant at $P<.05$.

APPENDIX TABLE 7. Assessment of effect modification of the AKI-outcome relationship by age, STAT surgical severity score, cardiopulmonary bypass time, and cyanotic heart disease

\begin{tabular}{|c|c|c|c|c|c|}
\hline \multirow[b]{2}{*}{ Outcome } & \multirow[b]{2}{*}{ AKI stage } & \multicolumn{4}{|c|}{$P$ value for interaction term of AKI and potential effect modifier } \\
\hline & & $\overline{\text { Age }>1}$ & STAT score $\geq 3$ & CPB time $>120 \mathrm{~min}$ & Cyanotic heart disease \\
\hline \multirow{2}{*}{$\begin{array}{l}\text { Death within } 30 \mathrm{~d} \\
\text { of surgery }\end{array}$} & No AKI vs $\geq$ stage 1 AKI & NA & NA & NA & NA \\
\hline & No/stage $1 \mathrm{AKI}$ vs stage 2 or greater AKI & .44 & .99 & .99 & .41 \\
\hline \multirow{2}{*}{$\begin{array}{l}\text { Readmission within } \\
1 \text { y of surgery }\end{array}$} & No AKI vs $\geq$ stage 1 AKI & .93 & .56 & .50 & .15 \\
\hline & No/stage $1 \mathrm{AKI}$ vs $\geq$ stage $2 \mathrm{AKI}$ & .65 & .68 & .20 & .71 \\
\hline
\end{tabular}

